\title{
Promotion of School Children Dietary Habits
}

\author{
Joy-Telu Hamilton-Ekeke ${ }^{1 *}$, Eunice Ogobiri Numa ${ }^{2}$, Love Eluan Abali ${ }^{3}$, Mercy Telu ${ }^{4}$ \\ ${ }^{I}$ Department of Science Education, Niger Delta University, Wilberforce Island, Bayelsa State, Nigeria \\ ${ }^{2}$ Department of Early Childhood Care and Primary Education Studies, Jasper Adaka Boro College of Education \\ Sagbama, Bayelsa State, Nigeria \\ ${ }^{3}$ Department of Science Education, Niger Delta University, Wilberforce Island, Bayelsa State, Nigeria \\ ${ }^{4}$ School of Agricultural Technology, Federal Polytechnic Ekowe, Bayelsa State, Nigeria
}

*Corresponding Author: Joy-Telu Hamilton-Ekeke, Department of Science Education, Niger Delta University, Wilberforce Island, Bayelsa State, Nigeria

\begin{abstract}
:
Aims/Background: Promoting the health of children through adequate diet is a panacea to healthy development and meaningful contributions to society. Schools are ideal settings for the inculcation of the knowledge of adequate diet in children. Schools have the opportunity to teach young people about food and nutrition thereby inculcating the importance of a balanced-diet for future health.
\end{abstract}

Method: The paper is a theoretical review that reviewed articles on health-promotion among children aged 10 - 12 years in terms of inculcating knowledge of balanced-diet and healthy choice of food, and also identified lapses in school-based intervention in the promotion of healthy eating and lifestyle. Health promoting school concept was also viewed as providing a framework for a whole-school-approach to food and nutrition.

Findings: In order for school children's dietary habits to be promoted; schools need to be health promoting. A health promoting school is one which enables students, staff, parents and the community it serves to work together towards a healthier life, school and society. The school curriculum, school environment, and ethos; all working in synergy to re-enforce healthy dietary messages making for a whole school approach to food and nutrition is necessary in the promotion of healthy dietary habits in children.

Conclusion: This paper contributes to the body of knowledge of inculcating healthy eating knowledge to school children by critically analysing empirical studies under three themes - dietary habits of school-aged children; factors influencing children's choice of food; and health-promoting-school, and raising under each theme some pertinent questions begging for answers.

Key terms: health promotion, children, dietary habits, advertising, nutrition education

Article Type: Theoretical Review

\section{INTRODUCTION}

Research studies show a growing concern about the diet of young people globally (Rugai and Hamilton-Ekeke, 2015). Data revealed for example, a movement away from regular meals, increase in snacking and low consumption of fruits and vegetables to a high consumption of fatty and sugary foods (Robert, Kingdom, Frith and Tudor-Smith, 1997; Umeh and Crabtree, 2006, Hamilton-Ekeke and Thomas, 2009 Hamilton-Ekeke, 2016). The level of evidence that a dietary factor could be involved in the promotion of or protection against the development of obesity has been put forward (Hamilton-Ekeke \& Thomas, 2005). Research has revealed a relationship between diet (a high consumption of energy dense-food) and obesity (Jung, 1997). Most of the debate about fat and carbohydrate contents of diet in relation to obesity centres on the effects of altering the reciprocal proportions of carbohydrate and fat in the diet on energy density, total energy intake and body weight (Katan, Grundy and Willett, 1997). Most obesity interventions have taken place in clinical settings. However, schools, also provide an opportunity for preventing and treating obesity (Sahota, Rudolf, Dixey, Hill, Barth and Cade, 2001). However, the lapse of most of the school-based intervention 
targets obese children (often volunteered by parents). Such targeting may increase stigmatisation of children at school.

It has long been recognised that schools can play a major role in dietary change (Hamilton-Ekeke, 2016; Young, 1993). Most school-based approaches have targeted obese children, with more success in primary school aged children (Parcel, Simons-Morton and Baranowski, 1988). Seidell (1998) suggested that more specific interventions targeted at the different factors influencing children's eating and physical activity behaviour (classroom education, food service, parents) may be needed in the tackling of obesity. Schools have the opportunity to teach young people about food and nutrition thereby inculcating the importance of a balanced diet for future health (Hamilton-Ekeke, Egumu, and Inengite, 2020). A health promoting school is one which enables students, staff, parents and the community it serves to work together towards a healthier life, school and society (Bowker, Crosswaite Hickman, McGuffin and Tudor-Smith, 1998). Health promoting school concept is viewed as providing a framework for a whole school approach to food and nutrition. This concept combines health education in the curriculum with the reinforcing effect of a supportive environment and ethos. Central to this - health education in the curriculum and supportive environment and ethos is 'how' curriculum content is implemented - teaching method, which should be underpinned by learning theories.

Stewart-Brown (2006) conducted a meta-review of more recent reviews of school-based interventions in relation to a range of health issues, notably healthy eating, physical activities, mental health and substance abuse. The study concluded that there was evidence of a positive impact of school-based interventions on the four health issues considered. Consequently, the review picked up on several methodological problems that have implications for the adequacy with which the health-promoting school has been, and might be, evaluated. One of these methodological problems is the impact of school on pupils' health. There are other sources of evidence on the impact of schools on pupil health, which are relevant to the health promoting school, but have not yet been incorporated into the evidence-base. One of these refers to studies that owe more to educational than health research, where the focus is on variation in pupil outcomes within school and between schools (West, 2006).

The theoretical position of Horne, Bowdery and Egerton (1998) on healthy eating for children combines the findings of contemporary work on learning and cognitive processes with the sociocultural insights of Vygotsky and Mead. In their view, the convergence in humans of classical and operant conditioning processes with the acquisition of language, including the ability to respond to and use names, verbal propositions and rules, exerts a pervasive influence on human behaviour. In the context of food choice for instance, they maintain that once children are verbally adept, they no longer react to foods merely as particular objects with inherent qualities of taste, smell, appearance, etc., but respond to them as named classes of items and respond to the verbalisations that they themselves and others make about those named classes. Nutrition educators acknowledge that a wide variety of factors influence children's eating behaviour. Factors that could influence a child's food choices are: nutrition knowledge, physiological needs, body image, food preferences, parental practices, peers, media, social norms, fast foods and personal experiences (Parmenter, Waller and Wardle, 2000). The literature on eating behaviour and its relation to nutrition knowledge is contradictory. Some researchers have shown that nutrition knowledge is highly and positively related to the behaviour towards nutrition (Pirouzina, 2001; Suzuki and Rowdder, 2002). Other researchers, however, found little correlation between nutrition knowledge and actual choices of healthy food (Story and Resnick, 1986; Halverson, 1987) hence the aim of this review.

\section{METHOD}

The paper is a theoretical review that reviewed articles on health-promotion among children aged $10-$ 12 years in terms of inculcating knowledge of balanced-diet and healthy choice of food, and also identified lapses in school-based intervention in the promotion of healthy eating and lifestyle. Health promoting school concept was also viewed as providing a framework for a whole-school-approach to food and nutrition. Three key themes emerged from the literature search for this paper and themes are:

- Dietary habits of school-aged children;

- Factors influencing children's choice of food;

- Health promoting school. 
Each of the four key themes was critically reviewed in terms of methods of data collection, sample, validity and reliability of instruments employed and interpretation placed on data. Emphasis was placed on synthesising methods, samples and ways in which data are interpreted. At the end of each reviewed theme are two sub-sections titled 'overview of key issues' and 'key emerging questions' were arrived at. The former is a summary of the criticisms of the various articles reviewed under the particular sub-section, while the latter are questions arising from the reviewed articles. This method of research was also employed in the following research (Bröder et al 2019; Sorensen, Van den Broucke, Fullam, Doyle, Pelikan, Slonska, \& Brand, 2012; Van Den Broucke, 2014).

\section{FindingS / DiSCUSSIONS}

\subsection{Dietary Habits of School-Aged Children}

There is a growing body of evidence that suggests that the chronic disease conditions of later life, in particular coronary heart disease, Type 2 diabetes and hypertension, have their origin in childhood (Lieberman, 2004; Hamilton-Ekeke, 2018). Poor diet in children is associated with a variety of problems including poor physical and intellectual development. The findings of Turtle, Jones and Hickman, (1997) reported the daily consumption of sugary foods like chocolate, sweets and fizzy drinks. Daily consumption of fresh fruit declined for girls and older pupils, but even in younger children, girls ate more fresh fruits than boys. Boys overall appeared to eat diets with higher proportions of convenience foods, but were far more physically active than girls. These data together with those presented by Hackett et al. (1997) suggested that despite the increased provision of healthy nutrition information there has been little change in food consumption. External factors such as peer group pressure and food advertising can direct young people away from healthy food choices.

\subsubsection{Children And Advertising}

Children learn about food and nutrition at school but additional sources of information are apparent in the wider environment, at home and in shops through media advertising. It has been found that adverts for food are most common during times when children are most likely to be watching; and those periods are dominated by advertisements for foods which are high in fat, sugar and salt (Dickinson, 2000). Dickinson (2000) who found out that there were 1,186 advertisements for food; more than four food adverts for every hour of output on ITV and Channel 4 and indeed, adverts for fatty and sugary foods outnumbered adverts for other foods.

The content of advertising specifically directed towards children has been previously investigated (Galst 1980). The main themes of advertising during 'children's programmes' were for toys, children's breakfast cereals (often high in sugar) other foods and snacks and chocolate and sweets. Unfortunately, some of which are food products that if eaten in excess can be detrimental to health. Because of the concentration of children's advertising on food items, attempts have been made to empirically investigate the effect on children's food choice by manipulating specific advertising material. Gorn and Goldberg (1982) showed children, age 5-8 years, either a 30 minutes cartoon interspersed with advertisements for sugary snacks and drinks or the same cartoon interspersed with advertisements for orange juice and fruits. The children watched the programmes over a two-week period and their snack choices were monitored. The study demonstrated that food choices tended to reflect the product advertising to which they had been exposed.

Galst (1980) investigated the snack food choice of 65 children between the ages of three and seven. A 30 minutes cartoon programme was interspersed with different food commercials and a healthy eating advertisement. The children saw the programmes every day for four weeks with or without comments from an adult promoting healthy-eating. The most effective way of counterbalancing the children's inclination to choose sugary snacks was a combination of the healthy message and comments from an adult who watched the programme with the children.

Additional factors have been shown to counterbalance the effects of advertising:

- The age of the child: younger children are more susceptible than older ones (Young 1990);

- Repetition and level of exposure: younger children find recognition of a familiar character in advertisements pleasurable; in older children increasing exposure has a negative effect (Young 1990);

- Parental mediation and discussion. Goldberg, Gorn and Gibson (1987) found that higher levels parental education and social class militated against the effects of television viewing and 
advertising. The evidence suggested that parents who are less well educated co-view more television with their children, and the extent of children-parent interaction subsequent to that exposure was less than for college educated parents.

Dickinson (2000) argued that television messages on food are not overwhelmingly 'unhealthy' compared to television adverts on food, as branded food products of course, dominate advertising. He was able to come to this conclusion by comparing the balance of different food groups on television food messages with the recommended balance of foods given in the Balance of Good Health. Dickinson also found that television presents a very confused, and on the whole contradictory, set of images about food and eating. What television tells us about food does not constitute ordered messages; it is, instead, a collection of disordered messages and because of the contradictory nature of television messages about food and eating, young people were able to find support and justification for a variety of conflicting diets and eating patterns, healthy and less healthy. The arguments so far support the role that television advertising has in providing information about food and influencing choice of food. Unfortunately, the information provided does not favour healthy eating and the 'Balance of Good Health' categorisation of food groups have been used as a justification of television messages being 'healthy'.

\section{$>$ Overview of Key Issues}

It is evident from the research studies that the dietary pattern of school children has not changed irrespective of the increased provision of healthy nutrition information (e.g. 5 A Day). Children tend to consume fewer classes of food in their choice combination and also tend to consume the 'same classes' of food most of the time. The macronutrient classes of food (carbohydrate, protein and fat), when consumed in excess, can be detrimental to health. The precursor of some chronic diseases starts in childhood and this is the time when dietary habits start to be formed.

\section{$>$ Key Emerging Questions}

A number of key questions regarding dietary habits of school-aged children require further research. In terms of the influence of nutrition education received at school, answers to the following questions need to be sought:

- Can classroom teaching of healthy eating influence children's choice of food?

- Can children demonstrate understanding of the various classes of food?

- Can children demonstrate the principles underpinning healthy eating?

- What is the place of advertisements in the choice of children's food?

- How does peer-group influence choice of children's food?

- How can parents be involved in their children's awareness of healthy eating?

\subsection{Factors Influencing Children Choice of Food}

The second theme reviewed in this paper is factors influencing children choice of food, evidence abound to the fact that wrong choice of food which most probably is as a result of lack of knowledge in balanced diet and healthy eating in school age children leads to obesity (Catford, 2003; Carter and Swimburn, 2004). Dietary awareness of children is subject to a range of complex interacting forces. During the formative years of childhood (0-5 years), parents largely influence the food choice of their offspring (Hamilton-Ekeke and Thomas, 2007). As childhood progresses, parental influence decreases in strength and additional forces start to compete. Peer pressure, the media, and nutrition education may make an impression on children's attitudes and choice of food.

Eves, Corney, Kipps, Noble and Lumbers (1997), in their study, established the factors affecting meal choice of primary school pupils by presenting photographs of a range of foods typically offered to them in their school canteen; the most often selected by the children for their preferred meal were pizza, chips, baked beans and ice cream with chocolate sauce. The main reasons for selecting these meals were the 'taste', 'familiarity' and 'healthiness'. The main reason why individual foods were 'liked' or 'disliked' was taste. Other factors included texture and dislike of a particular ingredient (e.g. cheese). The study used a methodology similar to the 'stacking box' method published by Ahlstrom, Baird and Jonsson 1990. The food items involved in the study were high quality-foods that are typically offered in school canteens. All foods were obtained from a primary school in the study area 
to ensure that the foods were representative. Children were presented with the food photographs (22 in total) in four groups, representing the main part of the meal (7 items), starch component (5 items), the vegetables ( 5 items) and the dessert (5 items). Children were asked to select one item from each group to make the meal that they would choose if offered the range of foods. The study took place amongst 123 primary school children (9-10 years old) in 14 schools. Each child was interviewed on a one-to-one basis. Methods were piloted prior to their final use and no changes were required, as children had no difficulties with the methods used. Instruments employed in the study were not validated.

Taste was also found to dominate the 'liked' breakfast choice of 10-16 years old school boys as investigated by Gummeson et al. (1996). Analysis of the meal items selected by the pupils indicated that the average percentage energy as fat in the selected meal was $44.2 \%$, which is higher than the $42.8 \%$ recorded for meals taken from school canteens in the National Food Survey (1995). One way to determine the misconceptions or alternative conceptions held by students on balanced diet and healthy eating might be to look at the factors that dominate their choice of food. The result of Eves et al. (1997) indicated that the reasons that children like foods differ but taste was mentioned most often in relation to both liking and disliking particular items. This is consistent with the results of Gummeson et al. (1996) who also found taste to be important in children's food choices. Both results thus indicated that the choices likely to be made by primary and even secondary school children resulted in fat levels that exceed current dietary recommendations, and that healthiness is not the main criterion used by most children in their meal selections. This might be as a result of lack of knowledge of adequate and healthy diet. Ahlstrom, Baird and Jonsson (1990) proposed that satisfaction with school meals might be improved if the variety of food offered was increased but Eves et al. (1997) slightly contrasted this by stating that the provision of more choices will not necessarily improve the nutritional value of a meal, however, if the extra choices are not carefully selected. A number of publications have indicated that the meals that children choose at school are high in fat (French, Story and Jeffery, 2001; Carter and Swinburn, 2004; Hamilton-Ekeke and Thomas, 2005; Hamilton-Ekeke and Thomas, 2008; Hamilton-Ekeke, 2016), and that poor choices of meals can result in a poorly balanced diet. An understanding of balanced diet and healthy eating is needed if more healthy meal options that children will choose to eat will be promoted.

\section{$>$ Overview of Key Issues}

It is evident from the research that healthiness was not the main reason of liking and choosing food. It is well known that the foundations for food choice are laid down in childhood. Poor dietary habits learned in childhood may persist into adult life. The dietary awareness of children is subject to a range of complex interacting forces. The factors, which influence children's food choices, are not well understood. Therefore to bring about changes in eating patterns it is necessary to have some understanding of how dietary habits are formed in early childhood and the extent to which these can be modified. It has been found (Eves et al., 1997) that it is easier to encourage healthy meal choices in primary schools, where choices are more constrained, and important to develop healthy eating practices at early age that will then be carried into later life.

The main emphasis of health and nutrition education has been on the role of diet in the prevention of disease in later life. However, young people have little perception of the future and therefore see little relevance of disease prevention. This makes the task of health and nutrition education more difficult. The reviewed studies show the continued preference of young people for snack items high in fat and sugar. Young people must be motivated to take responsibility for their own diets. To achieve this emphasis must be placed on the more immediate benefits to them. Nutritional requirements needed to maintain a healthy body alone have proved an inadequate mechanism in changing food consumption behaviour. It must therefore be recognised that factors other than knowledge and information play a more important role in food choice. For children these factors include parents, advertising and peers.

\section{$>$ Key Emerging Questions}

In order to promote 'healthiness' as a reason for choice of food of school-aged children, the following questions need to be addressed:

- 'What are the determinants of children's food preferences and rejections?'

- 'How can the school environment create barriers for health behaviours?'

International Journal of Humanities Social Sciences and Education (IJHSSE) 
- 'How can the school environment and ethos promote healthy behaviours?'

- 'What are the ways in which the school food environment can be improved?'

- 'How is the curriculum content on healthy eating implemented by the schoolteachers?'

\subsection{Health Promoting Schools}

Catford (2003 p.3) asserted that 'in promoting healthy weight we need to make a giant leap forward and act creatively and boldly, planners need to take a leaf from other public health strategies such as tobacco, road accidents and infectious diseases to see that education needs to under pin rather than lead action'. Schools are considered appropriate settings for health promotion for children, since the school may provide an environment for improving health, self-esteem, behaviours and life skills (Simone, Samuel, Richard and Aubrey, 2003). Schools can reach almost all children and adolescents during their first two decades in life and are ideal settings for influencing health (Hamilton-Ekeke, 2007).

A model for health promotion in schools, known as Health Promoting Schools (HPS), emerged from discussion during the 1980s under the auspices of the World Health Organisation (WHO). HPS was defined as a school constantly strengthening its capacity as a healthy setting for living, learning and working (WHO, 1998). The activities developed in the formal curriculum should be reinforced in all other elements that involve the school as a health promoting institution. It encompasses the informal curriculum, the hidden curriculum, the pastoral system developed by the school, the parallel curriculum and the general environment of the school. One example of a whole-school approach to food and nutrition has been the formation of a School Nutrition Action Group (SNAG). Such a group brings together individuals from within the school and the wider community, such as teaching and non-teaching staff, pupils, PTAs and representatives from relevant local support agencies. The general objectives of SNAG include:

- Review the curriculum provision;

- Examine conflicting health messages;

- Explore the relationship between diet and health;

- Examine the provision (including healthy options) and consumption of food throughout the school day;

- Provide good nutrition for pupils;

- Produce a school nutrition policy, which will make a positive contribution to health of pupils.

The question, which remains daunting, is: how knowledgeable are the different stakeholders that make up the SNAG membership of the principles of adequate diet and healthy eating. This is because it takes an adequate knowledge of the concept of balanced diet to function in a committee with such an enormous task as steering the cause of healthy eating. Thomas Benton, Keirle and Pearsall (1998) used seven qualifiers to judge schools that can qualify/pass as a HPS, the qualifiers are:

1. Involve pupils, parents, teachers and outside agencies in the development of health related policies and their implementation;

2. Ensure that every school policy is directed at every school member not just pupils;

3. Adopt an holistic approach, in that every school member including pupils, teachers, governors and support staff are involved in partnership;

4. Provide an opportunity for all staff to attend health-related in-service training on a regular basis;

5. Enhance links with families of pupils and with other professionals in the local community;

6. Be seen to practise what they preach, and for this to happen every school member needs to become a role model;

7. Appoint a health education co-ordinator (Thomas et al., 1998 p.129).

\section{$>$ Overview of Key Issues}

Pupils, and particularly secondary/post-primary pupils, have a range of sources of food during the school day. Many schools have food vendors and tuck-shops. Parents may provide snacks and packed 
lunches, while fast food vans selling snacks often park close to school gates, and local newsagents and fast food shops are other alternative sources of food. Thus, the challenge of a whole-school approach to food and nutrition is one not only of educating pupils to make more healthy choices but also to ensure that food availability throughout the school day encourages them to exercise these choices. The concept of health promoting school involves three main strands: curriculum provision, school ethos and environment and family and community involvement. There is certainly a need to involve the whole school community as Thomas et al. (1998) suggested.

\section{$>$ Key Emerging Questions}

- 'To what extent are pupils involved in the implementation of healthy eating policies in the school?'

- 'Do all stakeholders have an understanding of the concept of 'health promoting school'?'

- 'Is in-service training provided involving all adults in the school to explore their contribution to the initiative?'

- 'Does the school have a healthy school steering group involving teachers, non-teachers, governors, parents, pupils and community to oversee its development?'

\section{CONClusion}

Summarily, children's awareness of food and diet is influenced by a wide variety of interrelated factors including culture, socio-economic factors, parental influence, peer-group pressure, the media and nutrition education received at school. The continued preference of young people for foods high in fat and sugar suggests that the sensory quality of the food takes high priority in determining food selection. These factors are also modified by an individual's social, economic, cultural and educational background. Thus, in the long term, if health and nutrition education is to succeed the role of such factors in food choice and the establishment of food habits need to be more fully investigated and understood.

\section{REFERENCES}

[1] Ahlstrom R, Baird JC, Jonsson I. School children's preferences for food combination', Food Quality and Preference. 1990: 2: 155-65.

[2] Bowker S, Crosswaite, C, Hickman, M, McGuffin, S, Tudor-Smith, C. The healthy option - a review of activity on food and nutrition by UK schools involved in the European Network of Health Promoting Schools. Health Edu. 1998: 98: 135-41.

[3] Bröder, J., Okan, O., Bauer, U., Bruland, D., Schlupp, S., Bollweg, T.M., Saboga-Nunes, L., Bond, E., Sørensen, K., Bitzer, E-M., Jordan, S., Domanska, O., Firnges, C., Carvalho, G.S., Bittlingmayer, U.H., Levin-Zamir, D., Pelikan, J., Sahrai, D., Lenz, A., Wahl, P., Thomas, M., Kessl, F. \& Pinheiro, P. (2017). Health literacy in childhood and youth: a systematic review of definitions and models, BMC Public Health 17:419 Available at: https://doi.org/10.1186/s12889-017-4267-y Accessed 18th July 2020

[4] Bullen, K, Benton, D. A pilot study to explore the challenges of changing children's food and health concepts. Health Edu J. 200: 63: 50-60.

[5] Carter, M. and Swinburn, B. Measuring the 'obesogenic' food environment In New Zealand primary schools. Health Promotion Int. 2004: 19: 15-20.

[6] Catford, J. Promoting health weight - the new environmental frontier. Health Promotion Int. 2003: 18: 1.

[7] Dickinson, R. (2000). Food and eating on television: impacts and influences. Nutr \& Food Sci. 2000: 30: 24-9.

[8] Eves, A, Corney, M, Kipps, M, Nobel, C, Lumbers, M. Primary children's school meal choices Nutritional Implication. Int J of Hyg and Nutr in Foodservice and Catering. 1997: 1: 4-9

[9] French, SA, Story, M, Jeffery, RW. Environmental influences on eating and physical activities. Annual Reviews of Pub Health. 2001: 22, 309-35.

[10] Galst, JP. (1980). Television food commercials and pro-nutritional public service announcements as determinants of young people's snack choices. Child Dev. 1980: 51: 935-38.

[11] Goldberg, ME, Gorn, GJ, Gibson, W. TV messages for snack and breakfast foods: do they influence children's preferences?' J of Consumer Res. 1987: 5: 73-1.

[12] Gorn, GJ, Goldberg, ME. Some unintended consequences of TV advertising to children' J of Consumer Res. 1982: 4: 86-8. 
[13] Gummeson, L, Jonsson, I, Conner, MT, Sveensson, E. Assessing factors influencing food choice among 10-16 years old schoolboys. A pilot study with a stacking box method. J of Hum Nutr and Dietetics. 1996: 9: 219-29.

[14] Hamilton-Ekeke, J-T (2016) Sustainability of National Health Promotion policy through personal hygiene, Nigerian Journal of Health Promotion, 9: 191-195

[15] Hamilton-Ekeke, J-T, Thomas, M. (2009) Children's knowledge of balanced diet in the United Kingdom, Nigerian J of Sci. 2009: 43:73-1

[16] Hamilton-Ekeke, J-T. Social constructivist teaching and dietary knowledge, Germany: LAP LAMBERT Academic Publishing 2016: ISBN 978-3-659-50342- 9, Available athttps://www.lap-publishing.com/

[17] Hamilton-Ekeke, J-T, Thomas, M. Pre-adolescence understanding of carbohydrate and fat classes of food. Women in Edu Network. 2005: 2: 10-5

[18] Hamilton-Ekeke, J-T. Malnutrition and under-nutrition: two contemporary health problems in Nigeria, Nigerian J of Health Edu, 2018: 29: 133-46

[19] Hamilton-Ekeke, J-T, Thomas, M. Primary children's choice of food and their knowledge of balanced diet and healthy eating, British Food J. 2007: 109: 457-68

[20] Hamilton-Ekeke, J-T, Thomas, M. Evaluation of a pilot study on student's conceptual understanding and practical skills acquisition of dietary knowledge,

[21] Int J of Health Promotion and Edu. 2008: 46: 142-50

[22] Hamilton-Ekeke, J-T, Egumu, AC, Inengite, I. The teaching of health education as a secondary school subject in Bayelsa State, Nigeria, J of Edu and Learning. 2020: 14: 8-4

[23] Halverson, LS. Relationships among nutrition knowledge, attitudes and behaviour of Appalachian Middle School children', PhD dissertation, the Ohio State University, OH. 1997

[24] Horne, PJ, Lowe, CF, Bowdery, M, Egerton, C. The way to healthy eating for children', British Food J. 1998: 100: $133-40$

[25] Jung, RT. Obesity as a disease, British Medical Bulletin. 1997: 53: 307-21

[26] Katan, MB, Grundy, SM, Willett, WC. Should a low-fat, high-carbohydrate diet be recommended for everyone? Beyond low-fat diets. New England J of Med. 1997: 337: 563-67

[27] Liebermann, LD. Strategies in the health education - healthy eating and exercising to reduced diabetes. Health Edu \& Behaviour. 2004: 31: 1-5

[28] Parcel, GS, Simons-Morton, BG, O’Hara, NM, Baranowski, T. School-based programmes to prevent or reduce obesity', In Kranegor N.A., ed. Childhood Obesity: a Bio Behavioural Perspective. Telford: Caldwell, N.J. 1988. pp 143-47.

[29] Parmenter, K, Waller, J, Wardle, J. Demographic variation in nutrition knowledge in England. Health Edu Res. 2000: 15: 163-74.

[30] Pirouznia, M. The association between nutrition knowledge and eating behaviour in male and female adolescents in the US. Int J of Food Sci and Nutr. 2001: 52: 127-32.

[31] Robert, C, Kingdom, A, Frith, C, Tudor-Smith, C. Young People in Wales: Lifestyle Changes 1986-1996. Health Promotion Wales Technical Report no. 24, Health Promotion Wales, Cardiff. 1997.

[32] Rugai, J. and Hamilton-Ekeke, J-T (2015). Enhancing the teaching-learning process through the improvement of healthful school environment, International Journal of Current Research, 7(12): 2377723780

[33] Sahota, P, Rudolf, MCJ, Dixey, R, Hill, AJ, Barth, JH, Cade, J. Evaluation of implementation and effect of primary school based intervention to reduce risk factors for obesity. British Med J. 2001: 323: 1-4.

[34] Seidell, JC. Dietary fat and obesity: an epidemiologic perspective', American J of Clinical Nutr. 1998: 67: 546S-550S.

[35] Simone, TM, Samuel, TM, Richard, GW, Aubrey, S. Association between health promoting schools' policies and indicators of oral health in Brazil. Health Promotion Int. 2003: 18: 3-9.

[36] Sorensen, K., Van den Broucke, S., Fullam, J., Doyle, G., Pelikan, J., Slonska, z., \& Brand, H., (2012). Health literacy and public health: A systematic review and integration of definitions and models. BMC Pubic Health, 12, 80. Available at http://www.biomedcentral.com/1471-2458/12/80 Accessed on the 12 of July, 2020.

[37] Stewart-Brown, S. What is the evidence on school health promotion in improving health or preventing disease and, specifically, what is the effectiveness of the health promoting school approach?' WHO Regional Office for Europe (Health Evidence Report); Copenhagen 2006. Available at: www.euro.who.int/ document/e88185.pdf.

[38] Story, M, Resnick, MD. Adolescents' views on food and nutrition. J of Nutr Edu. 1986: 18: 188-92. 
[39] Suzuki, Y, Rowedder, M. Curriculum system and understanding of nutrition in school children. Int $\mathbf{J}$ of Consumer Studies. 2002: 26: 249-55.

[40] Thomas, M, Benton, D, Keirle, K, Pearsall, R. A review of the health promoting status of secondary schools in Wales and England. Health Promotion Int. 1998: 13: 121-29.

[41] Turtle, J, Jones, A, Hickman, M. Young People and Health: The Health Behaviour of School-Aged Children. A Report of the 1995 Findings, Health Education Authority, London. 1997.

[42] Umeh, K, Crabtree, L. Is fruit and vegetable intake in children a rationalist choice? British Food J. 2006: 108: 859-74.

[43] Van Den Broucke, S., (2014). Health literacy: a critical concept for public health. Archives of Public Health. 72, 10. Available at http://www.archpublichealth.com/content/72/1/10 Accessed on the 11 of July, 2020.

[44] West, P. School effects research provides new and stronger evidence in support of the health-promoting school idea. Health Edu. 2006: 106: 421-24.

[45] WHO's Global School Health Initiative: Health Promoting Schools, a Health Setting for Living, Learning and Working (WHO/HPR/HEP 198.4), WHO, Geneva. 1998.

[46] Young, I. Healthy eating policies in schools: an evaluation of the effect on pupils' knowledge, attitudes and behaviour. Health Edu J. 1993: 52: 3-9

\section{AUTHOR'S BIOGRAPHY}

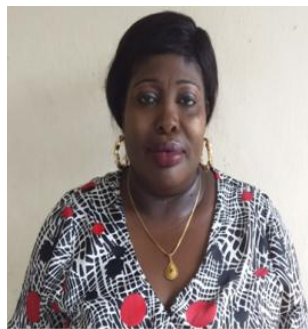

Joy-Telu Hamilton-Ekeke, She is an Associate Professor of Health Education in the Department of Science Education, Niger Delta University, Wilberforce Island, Bayelsa State, Nigeria. She holds a PhD degree in Health Education from the University of Wales Aberystwyth United kingdom. Her research interest include: teaching methodology, health education curriculum, quantitative and qualitative research methods, health literacy and health inequality amongst others.

Citation: Joy-Telu Hamilton-Ekeke, et.al. "Promotion of School Children Dietary Habits" International Journal of Humanities Social Sciences and Education (IJHSSE), vol 7, no. 12, 2020, pp. 28-36. doi: https://doi.org/10.20431/2349-0381.0712004.

Copyright: (C) 2020 Authors. This is an open-access article distributed under the terms of the Creative Commons Attribution License, which permits unrestricted use, distribution, and reproduction in any medium, provided the original author and source are credited. 